\title{
GEOGRAFÍA DE LA EXPULSIÓN DE LOS MORISCOS MUDÉJARES MURCIANOS
}

\author{
José Pascual Martínez **
}

Desde la publicación de la obra de Henri Lapeyre sobre la Geografía de la España morisca, se han estudiado repetidamente las fuentes sobre la minoría morisca para poder cuantificar, por una parte, a cuántos individuos afectaba el decreto de su expulsión y, por otra parte, cuántos finalmente abandonaron su suelo patrio desde el año 1609 al 1614 ${ }^{1}$. Aquí, vamos a focalizar nuestra atención en la distribución geográfica de los últimos moriscos murcianos expelidos, llamados «mudéjares antiguos» en la mayoría de las fuentes ${ }^{2}$, cuya comunidad había estado agrupada en aljamas desde hacía siglos.

Cuando se decretó la expulsión de los moriscos de los reinos peninsulares españoles, para «limpiarlos» de malos cristianos, se comenzó por el reino de Valencia, y sus moriscos fueron embarcados casi en su totalidad desde el 29 de septiembre al 7 de octubre de $1609^{3}$. A continuación, el 19 de enero de 1610, don Luis Fajardo, Capitán General de la Armada del Mar Océano, encargado de la expulsión de los moriscos del Reino de Murcia, informó al Consejo de Es-

* Quisiera agradecer a Francisco Chacón Jiménez, Catedrático de Historia Moderna de la Universidad de Murcia, la ayuda y los consejos ofrecidos a lo largo de la realización del presente artículo.

** Universidad de Murcia.

1. Henri LAPEYRe (2009), Geografía de la España morisca, Valencia, Universidad; FrANCISCO JAVIER Moreno DíAZ DEL CAMPO (2005), «Geografía de la expulsión morisca. Aproximación al análisis de la administración y venta del patrimonio de los moriscos expulsados de la Corona de Castilla», en Chronica nova: Revista de historia moderna de la Universidad de Granada, $\mathrm{n}^{\circ}$ 31, pp. 379-426; RAFAel Benítez (2009), «La geografía de la España morisca», en Cartas de la Goleta, 2. Actas del Coloquio Internacional "Los moriscos de Túnez", Túnez, pp. 65-82.

2. Cf. BERnARD Vincent (2013), «Los mudéjares antiguos», en FrancisCo CHACón Jiménez y SiLVIA Evangelisti (coords.), Comunidad e identidad en el mundo ibérico = Community and Identity in the Iberian World: one-day Simposium in Honour of Jim Casey, Universitat de València, Universidad de Granada, Universidad de Murcia, pp. 39-51.

3. En FrANÇOIS MARTínEZ (1999), La permanence morisque en Espagne après 1609. discours et réalités, Villeneuve d'Ascq, Presses universitaires du Septentrion, donde se publican íntegramente los decretos. 


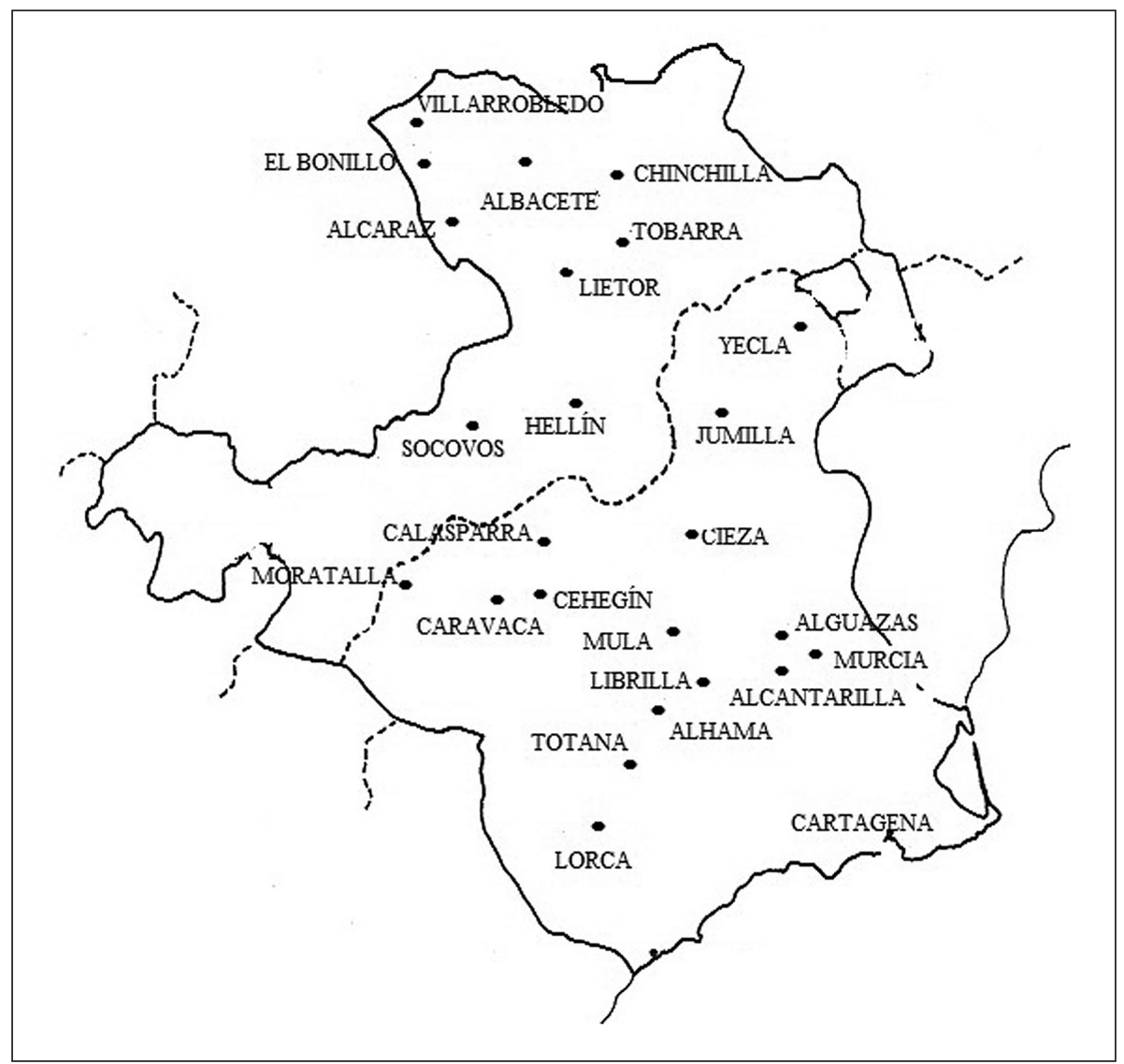

Mapa 1. Lugares de expulsión de moriscos granadinos en el antiguo reino de Murcia.

tado de que los bandos de expulsión habían sido publicados donde correspondía. Desde el 27 de febrero hasta el 20 de marzo de 1610, se embarcaron en Cartagena no menos de 6.142 moriscos granadinos moradores del reino murciano ${ }^{4}$. Mientras se embarcaban los expulsados de Castilla, todavía no se había decidido qué hacer con los moriscos mudéjares murcianos.

4. Cifra que se aproxima bastante a los 6.552 señalados por Cascales. FrANCISCO CASCALES (1621), Discursos históricos de la muy noble y muy leal ciudad de Murcia y su reino, $2^{\mathrm{a}}$ ed. de 1775, Murcia, p. 327. Cf. MANUEl LOMAS CORTÉS (2011), «El embarque de los moriscos en el puerto de Cartagena (1610-1614)», en Áreas. Revista Internacional de Ciencias Sociales, n 30, pp. 85-99; y MELCHOR Guerrero ArJona (2009), «IV Centenario de la expulsión de los moriscos lorquinos (1610-2010)», en Alberca: Revista de la Asociación de Amigos del Museo Arqueológico de Lorca, n 7 , pp. 109-129. 
Lapeyre contó cuarenta localidades con presencia morisca en el reino de Murcia a finales del Quinientos (siete en Albacete). Preparando la expulsión, se redujeron a veinte y siete, pero luego el nombramiento de fieles, para la venta de los bienes que se les embargaron, se incrementó hasta treinta y siete. Así, se vieron afectados en la expulsión de moriscos granadinos de Villarrobledo, El Bonillo, Alcaraz, Albacete, Chinchilla, Lietor, Tobarra y Hellín de la actual provincia de Albacete; Caravaca, Calasparra, Cehegín, Cieza, La Palma, Cartagena, Totana, Lorca, Mula, Librilla, Alguazas, Alhama, Jumilla, Moratalla, Yecla, Alcantarilla y Murcia con algunos lugares de su huerta, en la provincia de Murcia (ver mapas 1 y 2$)^{5}$.

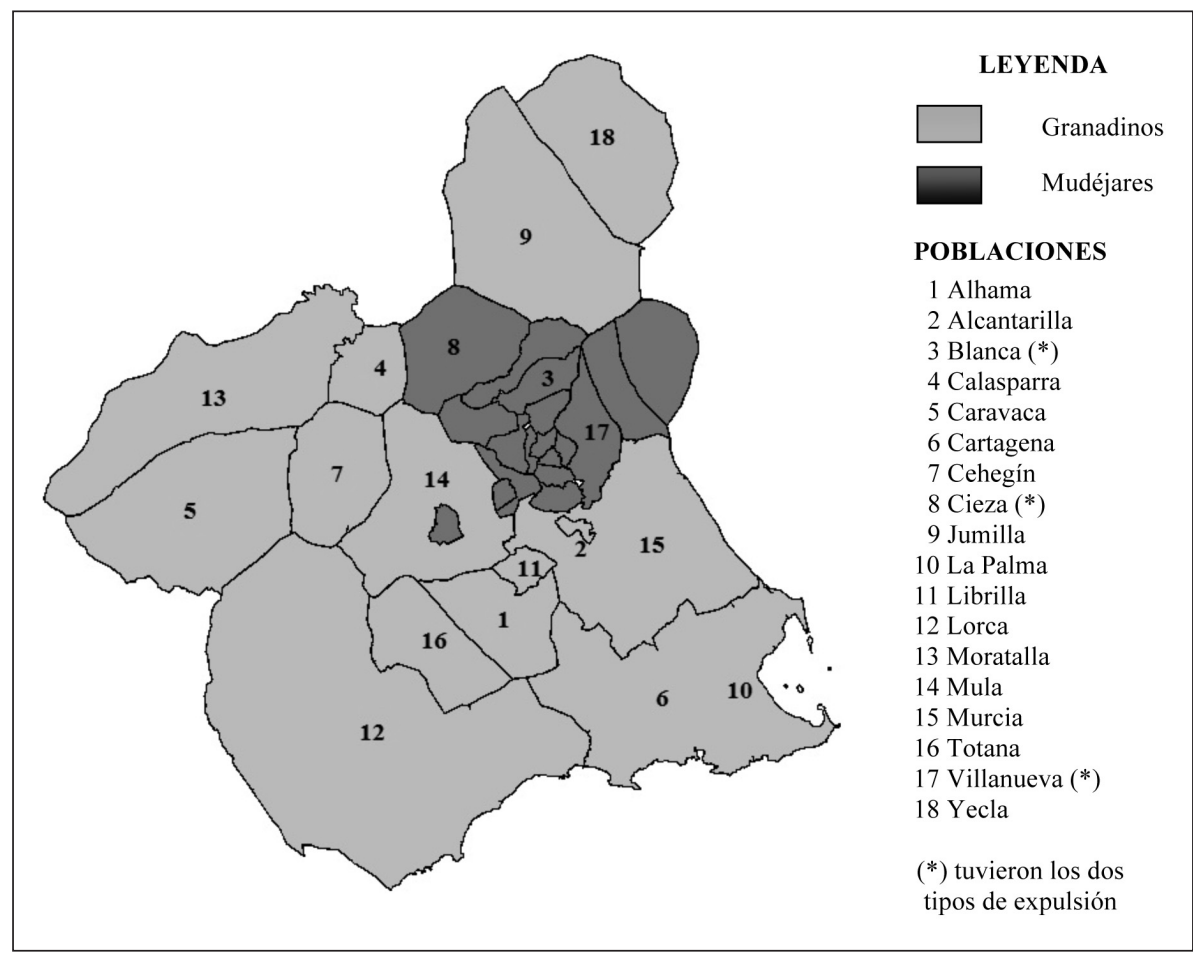

Mapa 2. Lugares de expulsión de moriscos granadinos en la actual provincia de Murcia.

Después de los moriscos granadinos - tras muchos titubeos y discusionesllegaba el turno a los llamados «mudéjares antiguos» del reino murciano. Lapeyre afirmó que los mudéjares salieron de Socovos, Abanilla, Abarán, Blanca, Ricote, Ulea, Ojós, Molina de Segura, Archena, Fortuna, Lorquí, Villanueva del Río

5. Cf. Lapeyre, H. (2009), pp. 150 y 211. Cf. Moreno Díaz del Campo, F. J. (2005), p. 405. 
Segura, La Puebla de Mula, Pliego, Albudeite y Campos del Río. El proceso de expulsión y destierro de estos moriscos mudéjares ha sido estudiado ampliamente, en sus líneas generales, en los últimos años ${ }^{6}$. Al principio el Consejo de Estado sólo había considerado la expulsión de los pobladores de Valle de Ricote. No obstante, a la vez que estos, también salieron los de Socovos, y fue publicado el bando en Pliego, Abanilla, Fortuna y Alguazas. Luego, se pensaba acudir a lugares de señorío para tratar con sus señores el procedimiento a seguir. Lamentablemente, los moriscos de las villas de Ricote no fueron los únicos -ni los últimos- expelidos en esta fase final, a pesar de que parezca indicarlo así la atención que se le ha prestado a este grupo y las repetidas referencias que se hacen de él en tantos estudios ${ }^{7}$. Es un síntoma de que todavía hay un vacío historiográfico acerca de los mudéjares murcianos, pues muchos de los lugares afectados aún no cuentan con un estudio sobre cómo fue su particular desarrollo ${ }^{8}$.

En el proceso de destierro, se siguió el plan propuesto por don Luis años atrás, en el que se comenzaba por el Valle de Ricote y se proseguía por otros pueblos, hasta donde se pudiera llevar a cabo, sin chocar de frente con los poderes locales. Ante las trabas que la autoridad murciana cruzaba en la labor de don Luis, y las serías dificultades que el corregidor y el cabildo pusieron a su hijo, cuando aquel se marchó, el rey comisionó para la expulsión de los mudéjares al conde de Salazar, que comenzó a dirigir la operación desde Hellín, con mucho ímpetu, en diciembre de 1613, pero llegó hasta donde pudo, y pronto se marchó, dando por finalizada su misión.

Después de la llegada de las galeras del príncipe Filiberto y de 280 hombres del tercio de Lombardía, se publicó el edicto el 30 de noviembre en las seis localidades del Valle de Ricote, en Murcia, Hellín, Archena, Ferez y Socovos ${ }^{9}$

Después, el conde de Salazar mandó a su asesor don Jerónimo de Avellaneda, con Antonio Manrique y algunos soldados de su compañía, que visitase estos lugares para averiguar cómo se trataba a los moriscos durante su expulsión. Fueron el 10 de diciembre. A su vuelta a Cieza, se publicó un segundo

6. Es muy interesante la exposición de JORGE GIL (2011), «Expulsión y destierro de los moriscos mudéjares del Reino de Murcia (1610-1614)», en Áreas, no 30, pp. 65-82.

7. Cf. José María García Avilés (2007), Los moriscos del valle de Ricote, Universidad de Alicante; Francisco José Flores Arroyuelo (1989), Los últimos moriscos: (Valle de Ricote, 1614), Academia Alfonso X el Sabio, Murcia. LuIs Lisón Hernández (1992), «Mito y realidad en la expulsión de los mudéjares murcianos del valle de Ricote», en Áreas, n 14, pp. 143-170; GOVERT Westerveld, Concepción del Pilar Rabadán Martínez, Ángel Ríos Martínez (2001), Blanca, “El Ricote" de Don Quijote. Expulsión y regreso de los moriscos del último enclave islámico más grande de España. Años 1613-1654, Beniel (Murcia).

8. Con la intención de cubrir parte de este hueco, he publicado Los moriscos mudéjares de Pliego: Origen y expulsión de una comunidad, Editum, 2014.

9. Archivo General de Simancas (en adelante AGS), Estado, leg. 252, Cartagena, 23-XI-1613, el príncipe Filiberto al Rey; leg. 251, Hellín, 28-XII-1613, el Conde de Salazar a José de Ciriza; leg. 252, Hellín, 1-XII-1613, el conde de Salazar al duque de Lerma. 
bando para otras villas donde había también moriscos: Cieza, Molina, Alcantarilla, Alguazas, Cotillas, Pliego, Puebla de Mula, Albudeite, Campos, Ceutí, Lorquí, Fortuna y Abanilla, desde donde tendrían que partir para embarcarse en Cartagena en diferentes días, de modo que no se obstruyesen las posadas del camino, y fuese más fácil el despacho de su registro y embarcación ${ }^{10}$.

La marcha de Salazar a Madrid rebajó la presión, quedando en los comisarios que nombró la tarea de consumar lo empezado. Lo que harían según las milicias disponibles y el apoyo logístico que recibieran desde el puerto de Cartagena. Cuando todavía estaba en marcha la expulsión de los últimos moriscos mudéjares murcianos, el conde de Salazar marchó a Madrid y, el 25 de enero de 1614, dio cuenta de cómo había cumplido su tarea en el Reino de Murcia ${ }^{11}$. El 19 de febrero de 1614 dio comisión a Martín de Saavedra para que examinase cómo habían actuado los encargados de expulsar a los mudéjares murcianos ${ }^{12}$.

En ese momento, no podía hacer balance de cuántos mudéjares habían sido finalmente expulsados. Guadalajara escribió que zarparon unos dos mil quinientos moriscos adultos, ya que los hijos quedaron con los cristianos viejos. $Y$ señaló que, de los lugares de moriscos situados fuera del Valle se ausentaron muchos, ya que no se podía poner la guardia que se había dispuesto en las villas de Ricote, mientras que otros procuraron probar que eran cristianos viejos (ya muchos lo habían probado ante don Luis Fajardo) o se hicieron religiosos ${ }^{13}$.

Según Henri Lapeyre, los embarcados desde diciembre de 1613 a enero de 1614 serían, aproximadamente, unos 7.000 individuos $^{14}$. Para contrastar esta valoración, contamos, por un lado, con el número total de familias inscritas en el registro de las mitades, realizado por el contador Juan Bautista de Aguilera, desde 18 de diciembre de 1613 hasta el 21 de enero de 1614, que recoge 366 (unas 1.500 personas) de las 2.546 casas que había en el Reino. Para Manuel Lomas, entre enero y julio de 1614, partieron once embarcaciones, con un total de 2.472 personas, de acuerdo con los registros conservados. Según las noticias recogidas por el comisario Hurtado de Mendoza acerca del embarque de Cartagena, el porcentaje de expulsados para la ciudad de Murcia y su jurisdicción es de cero, para las villas del Reino, sin contar las del Valle de Ricote, es del 10,7 por ciento, mientras que para las seis villas de este último es de 30,8 por ciento ${ }^{15}$.

10. Marcos Guadalajara y Xavier (1614), Prodición y destierro de los moriscos de Castilla hasta el valle de Ricote, Pamplona, f. 63.

11. AGS, Estado, leg. 2644, Madrid, 25-I-1614, Carta de Salazar a Su Magestad.

12. Archivo Histórico Provincial de Murcia (en adelante AHPM), prot. 9.496, 19-II-1614, Madrid, Comisión del Conde de Salazar al doctor Martín de Saavedra Noguerol, para averiguar cómo actuaron los encargados de expulsar a los mudéjares murcianos.

13. Guadalajara y Xavier, M. (1614), f. 64r.

14. LAPEYRE, H. (2009), p. 212.

15. Cf. Lomas Cortés, M. (2011), p. 89. 


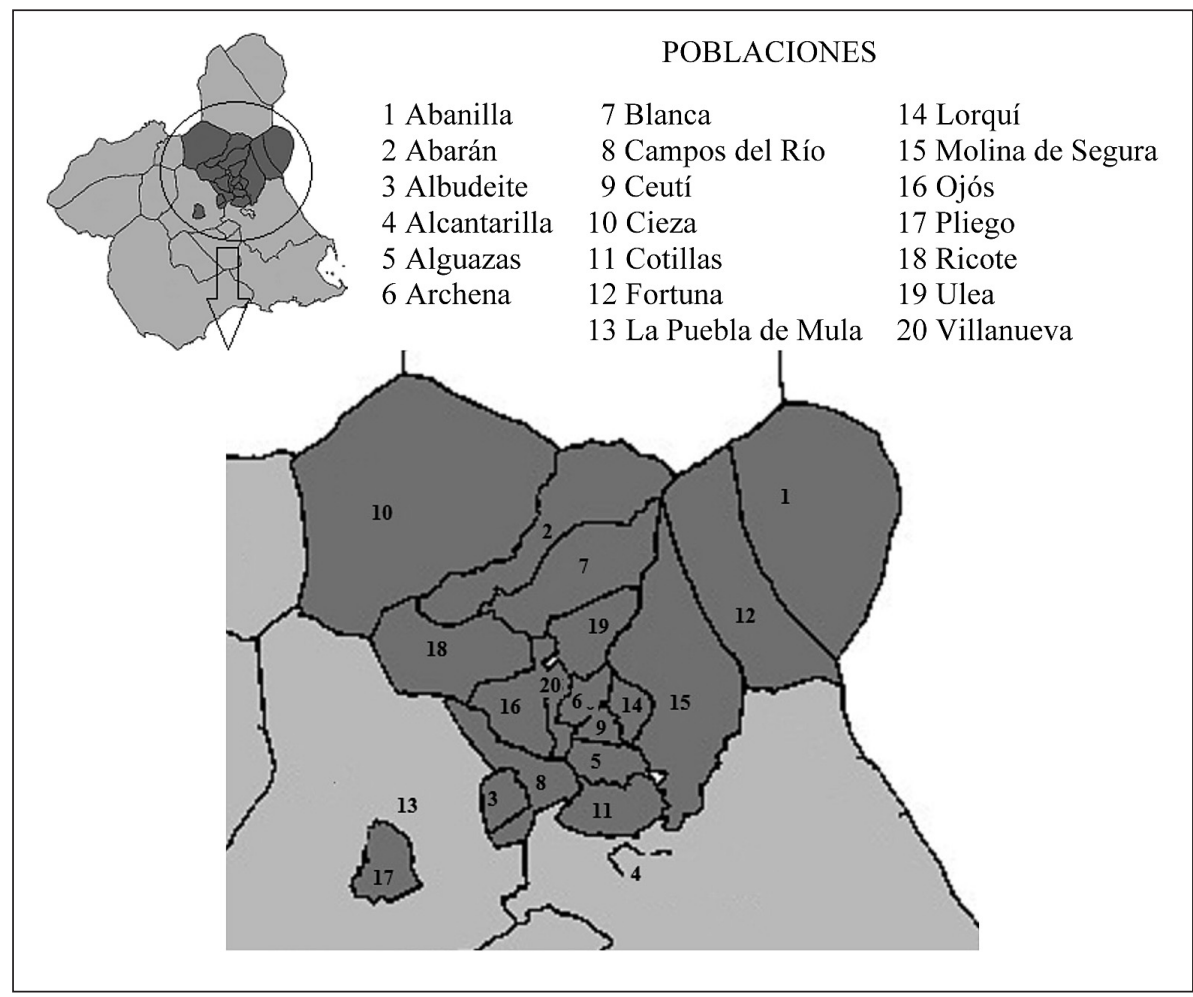

Mapa 3. Lugares de expulsión de mudéjares antiguos.

También para Jorge Gil, el tope máximo de expelidos estaría en los 2.500 mudéjares moriscos de los que hablaban Guadalajara y Bleda ${ }^{16}$, por lo que habría que reducir ampliamente la cifra de 7.000 mudéjares aportada por Lapeyre, que calculó partiendo de la lista de población de Luis Fajardo, hecha hacia abril de 1610, y valoró en unos 8.000 los mudéjares del reino. Sin embargo, si tenemos en cuenta los embarques estudiados por Jorge Gil, se deduce que a los mudéjares antiguos que vivían en los lugares incluidos en la primera categoría por Fajardo no se les molestó, y parece que tampoco fueron expelidos aquellos que residían en lugares de señorío del marqués de los Vélez (Puebla de Mula y Molina de Segura) y de Juan Usodemar (Alcantarilla) ${ }^{17}$. Lomas añade que también

16. Guadalajara y Xavier, M. (1614), f. 64r. Fray Jaime Bleda (2001) [1618], Corónica de los moros de España, Valencia, p. 1060; parece que este lo copia del anterior.

17. En el registro de las mitades no aparece ningún vecino de estos dos lugares. Aún así en la comisión del Salazar a Saavedra Noguerol sí se citan como lugares a los que se envió un comisario (AHPM, prot. 9.496). 
hay referencias en otros embarques de mudéjares de Alcantarilla, Cieza, Hellín, Molina de Segura y ciudad de Murcia, lo que demostraría que la expulsión de 1613-1614 afectó a toda la comunidad mudéjar y no sólo a una parte. Es factible que hubiera lugares donde la presión de los comisarios fuese inapreciable, o donde la influencia del señor protegiese a sus pobladores, y que algunos decidieran trasladarse a estos lugares y permanecer en el anonimato.

Simultáneamente a estos moriscos registrados en las mitades, se embarcarían una proporción de familias pobres, sin bienes que declarar, por lo que no aparecen en inventario. Además de que muchos de los incluidos en los bandos de expulsión huyeron y se escondieron para no cumplirlos ${ }^{18}$. Cambiaron de domicilio y no se embarcaron.

Como apunta Lomas, la encuesta de Fajardo no fue demasiado escrupulosa. Este no quería alertar a la población, y tenía prisa; por lo que pidió a los párrocos que enviaran secretamente las listas sin realizar diligencias públicas, y señaló la necesidad de revisar, caso por caso, las cifras propuestas ${ }^{19}$. Comprobación que quedó pendiente.

Para hacer un balance más aproximado, tanto de los moriscos que vivían en el reino murciano como de los que se fueron, es necesario estudiar la documentación de la Hacienda Real sobre la venta de los bienes confiscados a los moriscos expulsados de todo el Reino de Murcia y los pleitos que suscitaron, tal y como hemos examinado en el caso de Pliego ${ }^{20}$, tratando de discernir cuando se trata de moriscos granadinos y cuando se refieren a mudéjares. Por ejemplo, el Juez Doctor Mateo Cruzado Varrientos ya acudió a La Puebla de Mula el 1 de febrero de 1613, antes de la expulsión de los mudéjares. El 4 de febrero de 1618, el fiel Martín Montesinos entregó en sus cuentas la venta de bienes de quince moriscos de este lugar ${ }^{21}$. El 22 de junio de 1621, Agustín de Soto todavía hace relación de los «lugares de la nueva expulsión de los mudéjares», donde quedaban bienes requisados por vender, e incluía Puebla de Mula y Alcantarilla ${ }^{22}$.

Sucesivos estudios tendrán que ir repasando, matizando, los lugares y los moriscos implicados en cada uno de ellos. Por ejemplo, en el listado de las mitades aparecen diecisiete mudéjares expulsados de Albudeite, pero parece que

18. Cf. Pascual Martínez, J. (2014), pp. 216-222.

19. Lomas Cortés, M. (2011), pp. 89-90; AGS, Estado, leg. 227. Don Luis Fajardo a Felipe III, Murcia, 6-IV-1610.

20. Cf. Pascual Martínez, J. (2014), pp. 222-241.

21. AGS, Contadurías Generales, leg. 351-1, Bienes de moriscos de La Puebla de Mula, 4-II-1618.

22. AGS, Contadurías Generales, leg. 3025, Soto recoge Cotillas, Abanilla, Pliego, Cieza, Abarán Ojós, Ulea, Villanueva, Socovos, Puebla de Mula, Ceutí, Lorquí, Alguazas, Fortuna, Campos, Albudeite, Molina, Alcantarilla y Blanca: Y añade: «Todos estos son lugares de la nueva expulsión de los mudéxares. Y de los bienes de la vieja expulsión, que fueron los granadinos, tomó quentas Blas Gutiérrez Ossorio, por comisión del tribunal». En los lugares de granadinos menciona Murcia, Alhama, Mula, Chinchilla, Hellín, Lorca, Caravaca, Blanca, Socovos, Beas, Bonillo, Alcaraz, Villanueva, Lietor, Yuste, Cehegín, Calasparra y Moratalla. 
la población descendió unos cuarenta vecinos, según el informe mandado al Cabildo de Murcia, realizado por el fiel de los diezmos, fruto de su visita del 6 de febrero de 1614: «en el lugar de Albudeite ai çinquenta vecinos» $»^{23}$. Piénsese, que, antes de la expulsión, había unos 86 vecinos.

Juntamente con el repaso de estas fuentes de la Hacienda Real, es necesario el estudio de las fuentes locales: las actas capitulares de los ayuntamientos, los libros parroquiales y los protocolos notariales ${ }^{24}$. Por ejemplo, en las villas del Valle de Ricote se han conservado los protocolos con la escrituras de compraventa $^{25}$. En muchos lugares se han preservado también los libros parroquiales de desposorios y bautismos. En mi trabajo sobre los moriscos mudéjares de Pliego, he estudiado que un modo de eludir el destierro fueron los matrimonios pactados entre morisca y cristiano viejo, o simplemente no incluido en los bandos. El repaso de los motes de los desposorios entre finales de 1613 y mediados de 1614, con las velaciones correspondientes nos arrojan mucha luz, así como el estudio de las parejas que están procreando por esas fechas y luego se ausentan de la villa, volviendo a figurar en los libros parroquiales unos años más tarde, señal de una ausencia forzada del pueblo. Incluso se dan casos en los que los embarcados en Cartagena vuelven, pues, tras una interrupción lógica, siguen teniendo familia. También aparecen hijos de los que no se marcharon, que contraen matrimonio, así como líneas familiares que desaparecen para siempre ${ }^{26}$.

Acercarse en un estudio microhistórico a una población aporta mucha claridad acerca del modo de interpretar las fuentes, necesitadas de un estudio pausado y de una heurística profunda, sobre todo si se trata de descifrar unas estadísticas o relaciones numéricas de una época tan lejana, y recogida de segunda mano, sin el conocimiento o comprobación necesaria (caso de Fajardo y Pereda, que usan relaciones de mudéjares quizá derivadas de diferentes fuentes o informaciones) $)^{27}$.

En la carta del rey, fechada en Madrid el 22 de marzo de 1611, se trata de la expulsión de «los moriscos que llaman antiguos», que habían vivido en pueblos, barrios o calles separadas. A estos se les había tratado como tales, y habían pagado la farda y otros pechos de moriscos que no tributaban los cristianos viejos.

Antes de convertirse, los mudéjares pagaban «como moros» los impuestos de «servicio y medio servicio» y las «pechas», y quedaron libres de estos tri-

23. Archivo de la Catedral de Murcia, Diezmos, caja Mula y Albudeite.

24. Cf. Juan Bautista Vilar (1983), «Moriscos granadinos en el sur valenciano», en Estudis, no 9, pp. 15-48.

25. Isabel García díaz y Santiago Otero Mondéjar (2010), Documentos de los moriscos de Ricote y Ojós (1613), Editum.

26. Cf. Pascual Martínez, J. (2014), pp. 251-278.

27. Cf. Santiago la Parra López (1992), «Moros y cristianos en la vida cotidiana: ¿Historia de una represión sistemática o de una convivencia frustrada?», en Revista de historia moderna: Anales de la Universidad de Alicante, $\mathrm{n}^{\circ}$ 11, pp. 143-174. 
butos cuando se bautizaron, y pasaron a ser tratados como los demás cristianos. El impuesto de «servicio y medio servicio» era un impuesto directo que pagaba la comunidad mudéjar de Castilla de modo estable (150.000 maravedíes anuales), que se dividía («repartía») entre las poblaciones con presencia mudéjar, dependiendo del número de habitantes y de la riqueza de las morerías.

Las minorías judía y mudéjar castellanas debían sufragar, además, otro tributo propio de moros, fijado por los Reyes Católicos con motivo de la guerra de Granada, que se pagaba en castellanos de oro (nombre con que se designó la carga), moneda equivalente a 485 maravedíes. Con la caída del reino nazarí, y la expulsión de los judíos, los monarcas mantuvieron esta carga fiscal sobre los mudéjares, y recibió el nombre de «pechas». Su montante global superaba ampliamente al del «servicio y medio servicio» (en 1495, aproximadamente doce veces más).

Según el reparto del «servicio y medio servicio» en el Reino de Murcia en los años anteriores a la conversión ${ }^{28}$, los lugares con mayores morerías eran Alcantarilla y Molina de Segura, seguidas por La Puebla de Soto, la huerta de Murcia y la Arrixaca. Luego seguían las villas del Valle de Ricote, Ceutí, Pliego, Lorquí y Alguazas. Detrás estaban Fortuna, Albudeite, Campos del Río y Archena. La morería de Hellín era pequeña y aun eran menores las de La Puebla de Mula y Cieza ${ }^{29}$.

Hasta el momento de la conversión generalizada de los musulmanes murcianos, la mayoría se encontraba concentrada en diecisiete aljamas, muy bien delimitadas, que debían pagar los impuestos de «servicio y medio servicio» $\mathrm{y}$ "pechas», tributos que nos sirven a nosotros para calcular su población ${ }^{30}$. En 1501, los grupos más numerosos de mudéjares vivían en la huerta de Murcia, la Arrixaca, Alcantarilla, La Puebla de Soto y Molina de Segura. Basándose en las 3.763 «pechas» pagadas por los mudéjares de Castilla en el año 1501, aplicando el coeficiente de cuatro y medio, Ladero Quesada deducía que en ningún caso alcanzaban la suma de veinte mil mudéjares en el momento del famoso edicto de 1502 en toda Castilla. Mientras que en 1463, había musulmanes en once lugares del reino murciano, en 1501 se menciona su presencia en veinte y cinco. Parece tratarse, más que de un incremento poblacional, del asentamiento de los primeros granadinos ahuyentados de sus tierras por la conquista. Así, mientras que en 1495 se da cuenta de 675 «pechas», en 1501 son 782,

28. Cf. GonZalo Viñuales FerReIRo (2003), «El repartimiento del “servicio y medio servicio” de los mudéjares de Castilla en el último cuarto del siglo XV», en Al-Qantara XXIV, 1, pp. 179-202.

29. En tantos por ciento en 1501: Alcantarilla: 15,776; Molina del Segura: 12,135; Murcia y Arrixaca y La Puebla de Soto: 9,708; Val de Ricote: 7,281; Ceutí: 6,553; Pliego: 6,067; Lorquí: 5,825; Alguazas: 5,339; Fortuna: 4,368; Albudeite, Archena y Campos del Río: 4,126; Hellín: 2,427; La Puebla de Mula y Socovos: 0,970; y Cieza: 0,485.

30. Miguel Ángel Ladero Quesada (1981), «Los mudéjares de Castilla en la Baja Edad Media», en Actas del I Simposio Internacional de Mudejarismo, Teruel, pp. 349-390. 
lo que nos da idea de un incremento de casas. Con todo, aunque el Reino de Murcia estaba muy despoblado, el número de mudéjares era también muy pequeño ante la totalidad de la población.

La geografía de estas morerías repartidas por el antiguo Reino de Murcia coincide básicamente con los lugares de moriscos recogidos en los comentarios que Diego Molina y Juan Franco en su encuesta de 1533. Rastreando estas anotaciones, Francisco Chacón subrayó que «el cultivo de uva dedicada a pasa nos dibuja la geografía de la Murcia morisca» ${ }^{31}$. La población musulmana se estableció principalmente en la cuenca del río Segura (Valle de Ricote, vega media y vega baja) y el río Mula con su afluente el río Pliego (Campos del Río, Albudeite, La Puebla de Mula y Pliego). En esta misma información, se especifica que de igual forma se hacía uva pasa en Ojós y Cieza. Sabemos que aunque no se indica que en Ojós vivieran moriscos, estos eran mayoría. Tampoco se dice que los haya en Cieza (lugar donde antiguamente predominaban), o en las ciudades de Murcia, Lorca o Albacete (si bien no eran numerosos, sí eran un elemento importante, sobre todo en la huerta de la capital).

El censo de 1533 se realizó para repartir el pago del servicio ordinario y extraordinario según el número de vecinos pecheros. En principio, estaban excluidos los clérigos, los pobres y los hidalgos. Los noventa y nueve vecinos pecheros de Pliego eran moriscos. En el año 1528 habían pagado de servicio 5.840 maravedíes, siendo la sexta localidad del Reino de Murcia. A los realizadores de la encuesta -Diego de Molina y Juan Franco- les parecía que debían pagar en aquel momento 7.840, lo que supone un incremento del quince y medio por ciento. A pesar de lo afirmado por los encuestadores, la distribución de la propiedad, la calidad de sus términos y el engrandecimiento de la huerta permitieron que la población siguiera aumentando. La base de su economía procedía del cultivo de la morera, de la trilogía mediterránea de trigo, vid y olivo, y algo de lino y cáñamo, junto a la cría de algún ganado. líficos.

Se ha dicho siempre que los mudéjares eran sobrios, industriosos y pro-

«Las dos primeras condiciones serían a menudo fruto más de la necesidad que de la virtud, y la tercera ha de ponerse en tela de juicio, al menos en lo que se refiere al caso castellano, porque, en efecto, ¿cómo explicar que al parecer no haya aumentado la población de moriscos antiguos entre 1501 y 1608, a pesar de que tal es la tendencia demográfica común al siglo XVI?» ${ }^{32}$.

En la tabla 1 recojo la evolución de la población morisca de los veinte lugares que pagaban pechos de moros antes de la conversión, comparando la percepción sobre el número total de moriscos que se apuntan en el informe de 1533 (servi-

31. Francisco Chacón Jiménez (2000), Censo de población de 1533. Reino de Murcia, Universidad de Murcia, pp. 22-23.

32. Ladero Quesada, M. Á. (1981), p. 257. 
cio ordinario y extraordinario) y el censo de 1591 (servicio de millones). A partir de este dato, anoto la encuesta de Fajardo, en la que introduzco una columna intermedia con algunas modificaciones: la encuesta parece más exacta cuando recoge los datos sobre la población morisca, pero quizás se muestra menos escrupulosa al registrar el número de cristianos viejos, de modo que parece que unas veces se refiere a casas y otras al total de personas. He dejado al margen los lugares de la huerta de Murcia, ya que en ellos parece que no hubo expulsión.

En los casos de Abanilla, Alcantarilla, Alguazas, Campos del Río, Fortuna, La Puebla de Mula, Torres de Cotillas, Molina de Segura y Villanueva me inclino a pensar que el cálculo sobre el número de vecinos será más ajustado si el dato de cristianos viejos proporcionado por Fajardo lo tomamos como el número total de personas, mejor que como casas; pues en este supuesto, la población completa sería desproporcionada con los datos de 1591, tomados apenas dos décadas antes. Por ejemplo, sería inaudito que Villanueva del Segura pasase de contar 82 casas en el año 1591 a contar 166 (el doble) en el año 1610. En el año de 1607, Ricote debía pagar por el servicio ordinario y extraordinario 71.134 en maravedís ${ }^{33}$, y contaba con una población de 105 vecinos en el cómputo de 1610 de Fajardo, mientras que Villanueva estaba grabada con 39.198 maravedís.

Tabla 1. Evolución de la población morisca

\begin{tabular}{|c|c|c|c|c|c|c|c|c|c|}
\hline \multirow{3}{*}{ LOCALIDAD } & 1495 & 1501 & 1503 & 1533 & 1591 & 161 & & & 1618 \\
\hline & \multirow[t]{2}{*}{ PECHAS } & \multirow[t]{2}{*}{ PECHAS } & \multirow[t]{2}{*}{ PEONES } & \multirow[t]{2}{*}{ SERVICIO } & \multirow[t]{2}{*}{ SERVICIO } & \multirow[t]{2}{*}{ MUDÉJARES } & \multicolumn{3}{|c|}{$\begin{array}{c}\text { CRISTIANOS } \\
\text { VIEJOS }\end{array}$} \\
\hline & & & & & & & * 1 & FAJARDO & \\
\hline Abanilla & 68 & 70 & 104 & 150 & 314 & 301 & $10^{*}$ & 40 & \\
\hline Albudeite & 16 & 18 & 23 & 58 & 91 & 86 & 6 & 6 & \\
\hline Alcantarilla & 53 & 59 & $55^{34}$ & 103 & 243 & 197 & $70^{*}$ & 280 & 200 \\
\hline Alguazas & 19 & 29 & 43 & 80 & 166 & 69 & $24^{*}$ & 98 & 84 \\
\hline Archena & 21 & 21 & 22 & 43 & 103 & 86 & 12 & 12 & 54 \\
\hline Campos del Río & 10 & 16 & & 45 & 51 & 36 & $8^{*}$ & 32 & \\
\hline Ceutí & 37 & 47 & 35 & 68 & 82 & 34 & 7 & 7 & 27 \\
\hline Cieza & $8^{35}$ & 8 & $94^{36}$ & 164 & 348 & 34 & 500 & 500 & \\
\hline
\end{tabular}

33. Este impuesto era personal y afectaba directamente al cabeza de familia o, en su ausencia, a la viuda con hijos.

34. No se realiza el padrón y lo estiman los jurados.

35. Corresponden a 1498.

36. En 1507 tiene un total de 170 vecinos. 
Tabla 1. Evolución de la población morisca (continuación)

\begin{tabular}{|c|c|c|c|c|c|c|c|c|c|}
\hline \multirow{3}{*}{ LOCALIDAD } & 1495 & 1501 & 1503 & 1533 & 1591 & & 610 & & 1618 \\
\hline & \multirow[t]{2}{*}{ PECHAS } & \multirow[t]{2}{*}{ PECHAS } & \multirow[t]{2}{*}{ PEONES } & \multirow[t]{2}{*}{ SERVICIO } & \multirow[t]{2}{*}{ SERVICIO } & \multirow[t]{2}{*}{ MUDÉJARES } & \multicolumn{3}{|c|}{$\begin{array}{c}\text { CRISTIANOS } \\
\text { VIEJOS }\end{array}$} \\
\hline & & & & & & & * $\mathrm{F}$ & AJARDO & \\
\hline Fortuna & 31 & 29 & & 74 & 178 & 156 & $14^{*}$ & 54 & \\
\hline Hellín & & & & 507 & 869 & 78 & 800 & 800 & \\
\hline La Puebla de Mula & $21^{37}$ & 19 & & 51 & 40 & 47 & $9^{*}$ & 36 & \\
\hline Lorquí & 33 & 37 & 37 & 52 & 50 & 36 & 3 & 3 & \\
\hline Molina de Segura & 45 & 59 & & 111 & 85 & 38 & $52^{*}$ & 206 & 75 \\
\hline Pliego & 31 & 43 & $40^{38}$ & 99 & 251 & 267 & 59 & 59 & \\
\hline Socovos & $6^{39}$ & 14 & $18^{40}$ & 62 & 164 & 138 & 30 & 30 & \\
\hline Torres de Cotillas & & & 37 & 49 & 65 & 14 & $29^{*}$ & 115 & 12 \\
\hline Ricote & 177 & 200 & $77^{41}$ & 107 & 148 & 101 & 4 & 4 & \\
\hline Abarán & & & 30 & 65 & 136 & 166 & 5 & 5 & 93 \\
\hline Blanca & & & 86 & 151 & 203 & 208 & 3 & 3 & \\
\hline Ojós & & & 30 & 48 & 91 & 71 & 3 & 3 & \\
\hline Ulea & & & 23 & 30 & 49 & 59 & 1 & 1 & \\
\hline Villanueva & & & 23 & 28 & 82 & 101 & $16^{*}$ & 65 & \\
\hline TOTAL & 576 & 669 & 740 & 2.145 & 3.809 & 2.323 & 1.665 & 2.359 & \\
\hline
\end{tabular}

$\left(^{*}\right)$ En esta columna intercalada, se hace un ajuste de casas por considerar que, en esos casos, las cifras recogidas en el informe de Fajardo se refieren a vecinos totales ${ }^{42}$.

37. Corresponden a 1498.

38. En 1507 posee 55 vecinos.

39. Corresponden a 1498. Tiene entonces un total de 27 vecinos.

40. En 1507 posee 25 vecinos.

41. En 1507, Archivo Histórico Nacional, Órdenes Militares, Uclés 1072 C, Visitas de la Orden de Santiago. En 1603 las seis villas cuentan su conjunto 232 vecinos.

42. Fuentes: Años 1495 y 1501 en AGS, CMR, $1^{a}$ época, legs. 42 y 45: en Miguel LADERo QueSADA (1972-73), «Datos demográficos sobre los musulmanes de Granada y Castilla en el siglo XV», en Anuario de Estudios Medievales, $\mathrm{n}^{\circ} 8$ (Barcelona), pp. 481-490. Año 1503 del Padrón para el reparto de seiscientos peones para la guerra del Rosellón, AMM, A. Cap. 1502-1503, sesión 16II-1503, ff. 175v-176r. Censo de 1533 en AGS, CC. GG., leg. 768, f. 317, en CHACÓN JiméNEZ, F. (2000). Año 1591 en AGS, CC, leg. 2159. Año 1610 en AGS, Estado, leg. 227, Relaçión del número de moriscos que ay en el Reyno de Murcia desçendientes de los que se convirtieron antes de la reduçion general, que llaman mudéjares. Para 1618, AGS, Diversos de Castilla, Libro 25. CC, leg. 23, nº 1, en LUIS LISÓN HERNÁNDEZ (1992), p. 154. 
En la tabla 2 observamos que la proporción entre la contribución de 1607 y la población de 1591 (resultado también de las pesquisas para el pago de Servicio ordinario y extraordinario) es la misma. En el intervalo de 1591 a 1610, Ojós y Ricote pierden población, quizá por la expulsión de moriscos granadinos, o la huida de algunos vecinos a la gobernación de Orihuela. Sería llamativo que en el mismo intervalo Villanueva doblara su población, cuando sabemos que esta villa y Blanca sufrieron también el destierro de los granadinos.

\section{Tabla 2. Servicio ordinario y extraordinario en 1607 (en maravedíes) y población en 1591 y $1610^{43}$}

\begin{tabular}{lcrrc}
\hline LOCALIDAD & CONTRIBUCIÓN 1607 & 1591 & 1610 & FAJARDO \\
\hline Ulea & 23.207 & 41 & 60 & 60 \\
Villanueva & 39.198 & 82 & 117 & 166 \\
Ojós & 44.041 & 91 & 74 & 74 \\
Abarán & 64.916 & 136 & 169 & 169 \\
Ricote & 71.134 & 148 & 105 & 105 \\
Blanca & 97.770 & 203 & 211 & 211 \\
\hline TOTAL & & 701 & 736 & 785 \\
\hline
\end{tabular}

También se corrobora este hecho si comparamos con los datos de población que poseemos pata algunos lugares (por ejemplo, Alcantarilla y Molina de Segura) correspondientes al año 1618, en los que si el total de vecinos cristianos viejos se tomara como número de casas, la expulsión habría sido mucho más radical (tabla 1 ).

Sin embargo, en el resto de poblaciones, parece que el dato expuesto sobre el número de cristianos viejos debe referirse mejor al número de casas que al número total de personas, como se deduce de mi estudio pormenorizado de la expulsión morisca en Pliego; pues, del análisis de las fuentes y los censos nacionales, podemos concretar que los vecinos que se vieron finalmente obligados a emigrar de la villa fueron unos 157 vecinos. Un resultado similar aparece al examinar los libros de sacramentos de la iglesia de Santiago de Pliego, comprobando que -junto a los que manifiestan nominalmente las fuentes- hay otros parientes que dejaron de vivir en la villa en las mismas circunstancias; de los que sólo algunos volvieron, bien para restablecerse o para contraer matrimonio con familiares, mientras que otros permanecieron clandestinamente en otras villas cercanas ${ }^{44}$.

43. Fuente: Archivo Municipal de Cartagena, Caja 248, n 3 (recogido en Francisco Velasco HerNÁNDEZ (2002), «La presión fiscal del siglo XVII en el reino de Murcia: viejas y nuevas figuras tributarias», en Espacio, Tiempo y Forma, Serie IV, $H^{a}$. Moderna, t. 15, [pp. 85-104], p. 92.

44. Cf. Pascual Martínez, J. (2014), pp. 170 y 258-261. 
En la tabla 3, recojo el número de personas totales mudéjares y cristianos viejos. Para los cristianos viejos aplico el coeficiente cuatro. Añado una columna, contigua a la que recoge el total de personas que son cristianos viejos, que nos muestra el porcentaje de moriscos sobre el total de vecinos de la población. Si co-

Tabla 3. Totales mudéjares y cristianos viejos ${ }^{45}$

\begin{tabular}{|c|c|c|c|c|c|c|}
\hline \multirow{3}{*}{ LOCALIDAD } & \multicolumn{4}{|c|}{1610 (PERSONAS) } & \multirow{3}{*}{ CATEGORÍA } & \multirow{3}{*}{$\begin{array}{c}\% \\
\text { MITADES } 46\end{array}$} \\
\hline & PECHEROS & & CRIST. & $\%$ & & \\
\hline & MORISCOS & MUDÉJARES & VIEJOS $^{47}$ & MUDÉJARES & & \\
\hline Cieza & & 150 & 2.000 & 6,97 & $1^{\mathrm{a}}$ & 0 \\
\hline Hellín & & 350 & 3.200 & 9,86 & $1^{a}$ & 0 \\
\hline Torres de Cotillas & & 53 & 115 & 31,55 & $2^{a}$ & 21,4 \\
\hline Molina de Segura & mayoría & 170 & 206 & 45,21 & $2^{a}$ & 0 \\
\hline Alcantarilla & mayoría & 594 & 280 & 67,96 & $2^{a}$ & 0 \\
\hline Alguazas & todos & 228 & 98 & 69,94 & $2^{a}$ & 1,4 \\
\hline Pliego & todos & 935 & 236 & 79,85 & $2^{\mathrm{a}}$ & 9,4 \\
\hline Ceutí & todos & 115 & 28 & 80,42 & $3^{\mathrm{a}}$ & 14,7 \\
\hline La Puebla de Mula & todos & 156 & 36 & 81,25 & $3^{\mathrm{a}}$ & 0 \\
\hline Socovos & todos & 534 & 120 & 81,65 & $3^{a}$ & 7,9 \\
\hline Campos del Río & todos & 161 & 32 & 83,42 & $3^{a}$ & 27,7 \\
\hline Villanueva & todos & 371 & 65 & 85,09 & $3^{a}$ & 45,5 \\
\hline Archena & todos & 290 & 48 & 85,80 & $3^{a}$ & 59,3 \\
\hline Lorquí & todos & 140 & 12 & 92,10 & $3^{a}$ & 2,7 \\
\hline Fortuna & & 684 & 54 & 92,68 & $3^{a}$ & 4,5 \\
\hline Albudeite & todos & 312 & 24 & 92,86 & $3^{\mathrm{a}}$ & 19,7 \\
\hline Ojós & & 268 & 12 & 95,71 & $3^{a}$ & 42,2 \\
\hline Ricote & todos & 374 & 16 & 95,90 & $3^{a}$ & 27,7 \\
\hline Abanilla & todos & 1.007 & 40 & 96,18 & $3^{a}$ & 5,6 \\
\hline Abarán & todos & 574 & 20 & 96,63 & $3^{a}$ & 21 \\
\hline Blanca & todos & 677 & 12 & 98,26 & $3^{a}$ & 21,1 \\
\hline Ulea & mayoría & 244 & 4 & 98,39 & $3^{a}$ & 59,3 \\
\hline TOTAL & & 8.387 & 6.658 & 55,75 & & \\
\hline
\end{tabular}

45. Fuentes: Censo nacional de 1533 en AGS, CC. GG., leg. 768, f. 317, en ChaCón Jiménez, F. (2000). El año 1610, AGS, Estado, leg. 227, Relaçion del número de moriscos que ay en el Reyno de Murcia desçendientes de los que se convirtieron antes de la reduçion general, que llaman mudéjares.

46. Datos de GIL, J. (2011), p. 75.

47. Aplicando el coeficiente de cuatro personas por casa. 
locamos los lugares según el porcentaje de mudéjares en cada localidad, comprobamos que quedan ordenados según las tres categorías de lugares establecidas por don Luis Fajardo, derivadas del grado de integración con la población cristiana vieja, de las que fray Juan de Pereda se hizo eco más tarde, y llamó «género». Vemos que son del primer grupo Cieza y Hellín, ciudades populosas que no superan el diez por ciento de presencia morisca. Son del segundo grado las villas que superan el treinta por ciento y no llegan al ochenta por ciento. Finalmente, los lugares que superan el ochenta por ciento pertenecen al «tercer género».

En la última columna se indica el porcentaje de expulsados según el registro de las mitades ${ }^{48}$, en el que no se anotó ningún mudéjar antiguo de Alcantarilla, Molina de Segura, La Puebla de Mula y Cieza. Aunque en estos lugares también fueron nombrados fieles para la gestión de bienes de moriscos expulsados, sólo el estudio de los libros de venta de estos bienes podrá aclarar si estos patrimonios eran de granadinos o de mudéjares antiguos afectados por el decreto del 19 de octubre de 1613. Así como en La Puebla de Mula y Cieza el número de perjudicados por este decreto sería muy pequeño, con la posibilidad de que todos fueran pobres y no llevasen nada que declarar para el registro de las mitades antes de embarcarse, el porcentaje y el número absoluto de cristianos nuevos de Alcantarilla y de Molina era relevante, aunque no fuera mayoritario, y no podríamos considerar a todos como pobres.

El registro de las mitades del contador Juan Bautista de Aguilera concluyó el 21 de enero de 1614, por lo que no incluye la mayoría de las ventas que algunos moriscos realizaron más tarde, cuando aprovecharon el auto dado por Salazar en Cieza el 4 de enero, en el que concedió otro plazo de 10 días para que pudieran vender sus haciendas aquellos que, estando incluidos en los bandos, no pudieron alistarse por estar ausentes o por otros motivos justificados, a la vez que concedía una amnistía a los remisos. Lisón encontró que en la villa de Cieza todavía había gente alistándose el mes de febrero ${ }^{49}$.

En el caso de Alcantarilla, llama poderosamente la atención que, de los 197 vecinos (594 personas, según Pereda ${ }^{50}$ ) moriscos registrados en 1610, ninguno esté anotado en el registro de las mitades, ya que esta población contaba desde antiguo con su morería y, hasta la expulsión final, seguía contando con un porcentaje de 67,96 de cristianos nuevos y estaba incluida en la segunda categoría. Según la noticia recogida por Lisón, en el año 1618 había en Alcantarilla 200

48. GIL, J. (2011), pp. 65-82.

49. Aparecen vendiendo bienes Juan Guzmán, Juan Tornero y Juan Pérez. Cieza, 1-II-1614. Ante el escribano Laurencio de Padilla. AHPM., prot. 9.496. Lisón HernándEZ, L. (1992), p. 151.

50. De las listas de los informes de Fajardo y de Fray Juan de Pereda se deducen unos coeficientes por familia muy bajos. Lisón señaló que Fajardo no debió incluir a los niños de menos de 10 años, ancianos e impedidos, y aplicó el coeficiente 5, quizá ya excesivo. Cf. Lisón HerNÁNDEZ, L. (1992), pp. 152 y 163. Pereda decía en el preámbulo de su informe: «Havrá entre ellos más de nueve mil personas desta gente, conforme al número de la lista que me dio don Luis Faxardo, echando a cada veçino tres personas. En el qual cómputo, o no se entran mugeres y niños o me parece que son muchos más». 
casas, 67 menos del total de población morisca y cristiana vieja que apunta Pereda $^{51}$. De hecho, en la comisión que el conde Salazar dio a Martín de Saavedra para que examinase cómo habían actuado los encargados de expulsar a los mudéjares murcianos el 19 de febrero de 1614, se puntualiza que:

«A la villa de Alcantarilla fue por comisario el alférez Luis Serrano Palomeque, con ochoçientos maravedís de salario, y Joan del Solar, con quinientos, por su alguaçil. Albiertese que en todo el tiempo que estubieron en esta villa no sacaron morisco ninguno con ser grande y auer muchos en ella. Ase de haçer averiguaçión como egecutaron su comisión» (la cursiva es mía $)^{52}$.

También Molina de Segura tuvo una presencia importante de musulmanes, siendo mayoritarios en 1533, con una presencia luego disminuida hasta 170 individuos moriscos frente a 206 cristianos, con una proporción de 45,21, clasificada en el segundo género. Dos fenómenos pueden explicar esta disminución de moriscos en Molina. Uno es la posibilidad de que, siendo lugar del marqués de los Vélez, hubiese sufrido una afluencia de nuevos pobladores, y una presión señorial tal que los labradores antiguos se vieran desplazados, como ocurrió en la villa de Alhama, también señorío del marqués, donde las familias de labradores mudéjares que moraban en el campo fueron desalojadas paulatinamente por nuevos colonos y por prisioneros de guerra tomados por los Fajardo en sus empresas granadinas, reducidos a una situación jurídica de servidumbre. Años más tarde, los mudéjares habían desaparecido por completo de Alhama, y hacia 1581 sólo vivían en ella veinte y cuatro familias granadinas, mientras había doscientos hogares de cristianos viejos ${ }^{53}$. También pudo ocurrir que muchos mudéjares antiguos fueran paulatinamente considerados como cristianos viejos.

Otro caso singular es el de Alguazas, lugar de la iglesia de Cartagena, donde en 1533 hay 80 casas de pecheros, todos moriscos. El hecho de que en 1610 sean sólo 69 los vecinos moriscos (habiendo disminuido del 100 al 36,77 por ciento) y aumentado hasta 98 las casas de cristianos viejos puede explicarse, en parte, por lo que recoge el censo de población de 1533:

«los quales tienen razonable pasada y buena huerta con abundancia de agua de riego, donde tienen moreras y cogen pan y arroz y otros frutos en razonable cantidad, y este lugar tiene dispusyçion y prinçipio de se poblar en vezinos más que agora tiene y acreçentar en faziendas porque tienen termino para hazer otra tanta huerta y le pueden dar riego» ${ }^{54}$.

51. LISÓN HERNÁNDEZ, L. (1992), p. 154.

52. AHPM, prot. 9.496 .

53. IldeFonso MozAs Agulló y JuAn Bautista VILAR (1977), «Un conflicto de señoríos en la España del siglo XVI: pleito entre la villa de Alhama de Murcia y su señor el marqués de los Vélez (15481592)», en Estudis, 6, pp. 27-69. Cf. FrANCISCO CHACÓN JiMÉNEZ (1983), «Los moriscos de Lorca y algunos más en 1571», en Anales de la Universidad de Murcia, XL, pp. 312-326.

54. Chacón Jiménez, F. (2000), p. 42. 
No obstante, es difícil explicar la disminución de vecinos de origen morisco con tan buenas perspectivas, teniendo una existencia «razonable pasada» y la circunstancia de que no siendo gente pobre, sólo haya uno y medio por ciento anotados en el registro de las mitades. Este fenómeno me lleva a pensar que hubo un traspaso de mudéjares a cristianos viejos en el momento en que los párrocos son encargados de alistar a los moriscos. Por lo menos de algunos de ellos, lo cual no era difícil, ya que, aunque su genealogía fuese claramente mudéjar, socialmente y étnicamente eran tan cristianos viejos, como los que gozaban desde antiguo de esa posición. En los lugares de mudéjares donde habían inmigrado pocos vecinos en los últimos cien años, los matrimonios mixtos con cristianos viejos eran muy difíciles, y no se podía paliar esta circunstancia si las localidades limítrofes tenían una composición demográfica semejante (piénsese en el caso de las villas del Valle de Ricote), por lo que la endogamia entre mudéjares en el momento de contraer matrimonio era muy importante, incidente que se esgrimiría luego como actitud de rechazo del cristiano nuevo a emparentar con cristiano viejo.

Incluso del conde de Salazar muchos mudéjares que habían sido alistados consiguieron ejecutorias, por lo que finalmente no fueron expelidos. Así hicieron, por ejemplo, Alonso Faura Ricarte y Diego Faura, y otros vecinos de Pliego, a los que don Bernardino les dio ejecutorias por las que los declaraba «no comprendidos» en los bandos de la expulsión ${ }^{55}$.

Comparando los datos aportados por el cobro de estos tributos de moros y los censos realizados para pagar impuestos años más tarde, comprobamos que una parte considerable de ese contingente estaba, ya a finales del siglo XVI, totalmente asimilado y se confundía entre la población cristiana vieja, en algunos casos con la ayuda de los párrocos, de las autoridades locales y de sus propios paisanos. Sin embargo, esta «ayuda» no fue igual en todos los lugares, pues, mientras las autoridades concejiles y la vecindad no cambiaban, los párrocos no tenían los mismos criterios y sensibilidad. Por ejemplo, en el informe del Padre Pereda se dice acerca de los mudéjares de Murcia capital:

«Esta ciudad, según la lista de don Luis tendrá asta ciento y siete mudéxares, en el varrio de Sant Antolín y San Ginés, de los quales no he oydo cosa mala, y en todo lo referido arriba en fauor desta gente testifican sus curas y más de 20 testigos, que affirman estar tan mezclados y enparentados que seria difficultosissimo distinguirlos y su expulsión en grave perjuicio de gente muy honrada enparentada con ellos, y que no se hallara uno puramente mudéxar que no tenga un quarto o más de xristiano viejo, y que se han portado como tales; que muchos de la ciudad antes del vando no savían que huuiesse allí mudéxares y assí pertenecen al primer género».

De Hellín se dice en el informe:

55. AGS, Contadurías Generales, leg. 345-1. Luego, presentaron en el tribunal de oidores del gobierno de Hacienda y Contaduría Mayor los pleitos correspondiente para pedir que se les devolvieran los bienes que les habían confiscado y vendido. 
«Esta villa es de más de 800 vecinos, y hay en ella un barrio que llaman el nuevo que tendrá hasta 350 mudéxares [unos 100 vecinos], de los quales testifican su cura, los religiosos de San Francisco que los han confesado y dos familiares del Santo Oficio de allí y otros once testigos, que son gente muy exemplar y tanto que pueden ser dechado de virtud y christiandad».

Sus vecinos son considerados de la primera categoría, a pesar de ser un grupo numeroso que vivía en un barrio propio. Sin embargo, así como los de Murcia tuvieron la protección de sus autoridades locales, a los de Hellín no les sirvió el amparo señorial y se vieron perjudicados por la estancia del conde de Salazar en su ciudad en el momento de llevar a efecto los edictos de expulsión. Los mudéjares tenían adversarios tenaces y fanáticos que no descansaban hasta ver cumplido su propósito. El conde de Salazar, don Bernardino de Velasco y Aragón, era uno de ellos y se mostró entre los más activos en este sentido. En su amplio informe del mes de septiembre de 1612 puso en duda la validez de los datos del Padre Pereda, manifestando que este religioso pertenecía a la misma orden que el monasterio que poseía bienes en la zona. El conde estaba convencido de la mala cristiandad de los moriscos por las demostraciones de piedad que exhibían desde la publicación del edicto. Incluso decía que los moriscos del Valle de Ricote tenían comunicación con Berbería. Además, tenían al comendador a su favor y ellos con sus demostraciones de cristianos supieron engañar a un fraile que vino a hacer una averiguación. Para el conde, exceptuar a estos moriscos amenazaba con arruinar toda la obra de la expulsión y proponía a cambio enviar a los moriscos a Francia ${ }^{56}$.

Guy Lemeunier señaló que en el año 1631 sólo cinco de las diez comarcas murcianas habían crecido respecto a 1591, sin embargo la otra mitad vio mermada su población: especialmente las afectadas por la expulsión de mudéjares en el año 1614, como Cieza, Valle de Ricote, la Vega de Molina, la cuenca de Fortuna-Abanilla (comarca del este) y la del río Mula. Recogía este autor una encuesta realizada en algunos lugares en el año 1618, para mostrar la imposibilidad que tenían algunas comunidades de pagar las cargas fiscales que se le imponían ${ }^{57}$.

Estudiando la tabla 4, comprobamos que la población ha disminuido en la mayoría de los lugares incluidos en la encuesta de Fajardo, pero ha crecido en Fortuna, Molina de Segura y Hellín, resultado quizá de una muy pequeña o nula incidencia de la expulsión de 1613-1614. También es escaso el saldo mostrado por el registro de las mitades en los casos de Alcantarilla y de Lorquí,

56. AGS, Estado, leg. 2.643, Informe de Salazar, 28-IX-1612; cf. LAPEYRE, H. (1959), p. 286, que lo publica en parte en el apéndice XIV. Cf. FrAnCiSCO CHACÓN JiménEZ (1982), «El problema de la convivencia. Granadinos, mudéjares y cristianos-viejos en el Reino de Murcia. 1609-1614», en Melanges de la Casa de Velázquez, t. XVIII/1, p. 132.

57. GuY LeMEUnier (2004), «Población y poblamiento en la región de Murcia (siglos XVI y XVIII). Censos de población y series bautismales», en Áreas, n 24, p. 86. Abanilla había descendido entre 1610 y 1618 de 311 a 90 vecinos. Alcantarilla de 267 a 126. Y Ojós de 74 a 13. Fuente: Archivo Municipal de Murcia, legs. 2010, 2011 y 2014 
Tabla 4. Incidencia de la expulsión de los mudéjares antiguos murcianos

\begin{tabular}{|c|c|c|c|c|c|c|c|c|c|c|}
\hline \multirow{3}{*}{ LOCALIDAD } & \multicolumn{5}{|c|}{1610} & \multicolumn{4}{|c|}{1631} & \multirow{3}{*}{1646} \\
\hline & \multirow[t]{2}{*}{ MUDÉJ. } & \multirow[t]{2}{*}{$\begin{array}{l}\text { CRIST. } \\
\text { VIEJOS }\end{array}$} & \multirow[t]{2}{*}{ TOTAL } & \multicolumn{2}{|c|}{ MITADES } & \multicolumn{2}{|c|}{ VECINOS } & \multicolumn{2}{|c|}{ EXPULSADOS* } & \\
\hline & & & & $\mathrm{N}^{0}$ & $\%$ & TOTAL & $\%$ & $\mathrm{~N}^{\circ}$ & $\%$ & \\
\hline Cieza & 34 & 500 & 534 & 0 & 0 & 413 & $-22,6$ & 34 & 100 & 448 \\
\hline Hellín & 78 & 800 & 878 & 0 & 0 & 897 & $+2,1$ & 0 & 0 & \\
\hline Torres de Cotillas & 14 & 29 & 43 & 3 & 21,4 & 16 & $-62,7$ & 27 & 100 & 12 \\
\hline Alguazas & 69 & 24 & 93 & 1 & 1,4 & 102 & $+9,7$ & 65 & 94,2 & 84 \\
\hline Molina de Segura & 38 & 52 & 90 & 0 & 0 & 99 & +10 & 0 & 0 & 73 \\
\hline Alcantarilla & 197 & 70 & 267 & 0 & 0 & 256 & $-4,1$ & 11 & 5,5 & 400 \\
\hline Pliego & 267 & 59 & 326 & 25 & 9,4 & 219 & $-32,8$ & 107 & 40 & 247 \\
\hline Ceutí & 34 & 7 & 41 & 5 & 14,7 & 34 & -17 & 7 & 20,5 & $27^{58}$ \\
\hline Puebla de Mula & 47 & 9 & 56 & 0 & 0 & - & - & - & - & \\
\hline Campos del Río & 36 & 8 & 44 & 10 & 27,7 & - & - & - & - & \\
\hline Villanueva & 101 & 16 & 117 & 46 & 45,5 & 83 & -29 & 83 & 82,1 & 75 \\
\hline Archena & 86 & 12 & 98 & 51 & 59,3 & 62 & $-36,7$ & 36 & 41,8 & 54 \\
\hline Socovos & 138 & 30 & 168 & 11 & 7,9 & 137 & $-18,4$ & 31 & 22,4 & \\
\hline Lorquí & 36 & 3 & 39 & 1 & 2,7 & 29 & $-25,6$ & 10 & 27,7 & 21 \\
\hline Fortuna & 156 & 14 & 170 & 7 & 4,5 & 186 & $+9,4$ & 7 & 4,5 & 192 \\
\hline Albudeite & 86 & 6 & 92 & 17 & 19,7 & - & & & 70 & \\
\hline Blanca & 208 & 3 & 211 & 44 & 21,1 & 86 & $-50,2$ & 125 & 60 & 80 \\
\hline Ojós & 71 & 3 & 74 & 30 & 42,2 & 40 & $-45,9$ & 34 & 47,8 & 24 \\
\hline Ricote & 101 & 4 & 105 & 28 & 27,7 & 70 & $-33,3$ & 35 & 34,6 & 63 \\
\hline Abanilla & 301 & 10 & 311 & 17 & 5,6 & 213 & $-31,5$ & 98 & 32,5 & 197 \\
\hline Abarán & 166 & 5 & 171 & 35 & 21 & 118 & $-30,9$ & 53 & 31,9 & 93 \\
\hline Ulea & 59 & 1 & 60 & 35 & 59,3 & 34 & $-43,3$ & 26 & 44 & 20 \\
\hline \multirow[t]{2}{*}{ Totales } & 2.323 & 1.665 & 3.988 & 366 & $15,7 \%$ & 3.094 & $-22,41$ & 789 & $33,96 \%$ & 2.180 \\
\hline & 10.453 & 6.660 & 17.113 & \multicolumn{2}{|c|}{1.647} & 12.376 & & \multicolumn{2}{|c|}{3.550} & 8.720 \\
\hline
\end{tabular}

* El tanto por ciento de los expulsados está calculado sobre la población morisca afectada ${ }^{59}$.

58. En 1654 dice el Ayuntamiento que son menos de 30, y se reducen a 14 en 1665.

59. FuENTES: El año 1610, AGS, Estado, leg. 227, Relaçion del número de moriscos que ay en el Reyno de Murcia desçendientes de los que se convirtieron antes de la reduçion general, que llaman mudéjares; el Vecindario de 1631 o de la sal, AGS, DGT, inventario 24, leg. 1.168. El año 1648 en AGS, DC, leg. 23, Averiguaciones para un reparto de juros, con una información considerada poco fiable. 
donde la diferencia entre censos es sólo de una decena de vecinos. En los casos de Archena y Ceutí ${ }^{60}$ casi son coincidentes los datos del registro de las mitades y la disminución de la población.

Sin embargo, en las villas del Valle de Ricote, Torres de Cotillas, Pliego y Abanilla el descenso de población muestra que en los registros de las mitades no estaban incluidos la mayor parte de los deportados, pues el descenso poblacional fue más acusado ${ }^{61}$. En mi estudio sobre la expulsión de Pliego concluyo que los expulsados de Pliego fueron unos 200 mudéjares, que son el 61,3 por ciento del total del vecindario. No se refleja en la cifra de 1631 porque muchas doncellas y viudas, para no ser expulsadas, contrajeron matrimonio con cristianos viejos o mudéjares no alistados, se instalaron en la villa y supusieron un aporte importante de vecinos, que contrarrestaba la salida de tantos moriscos.

El dato del Vecindario de la sal de 1631 para Cotillas parece incorrecto, y en lugar de 66 vecinos deberíamos considerar 16, pues en este lugar la expulsión redujo tanto el número de habitantes que en el año 1616 perdió el curato por no poder mantenerlo y su iglesia pasó a ser anejo de Alguazas. Los bautismos desde 1616 hasta 1650 oscilan entre uno y once ${ }^{62}$.

En Ulea y Ojós la diferencia de población y las casas embarcadas en Cartagena inscritas en las mitades, arrojan cifras muy similares a las del censo de 1631.

Un caso nuevamente atípico es el de Alguazas, en el que la pesquisa de Fajardo parecía que transfería cristianos nuevos a la condición de viejos, pero finalmente, parece que las cifras nos muestran un descenso considerable de vecinos, que el registro de las mitades no corrobora. Por lo que se ve, una vez más, la necesidad de llevar a cabo un estudio de las fuentes locales (pleitos, libros de sacramentos, etc.).

Vemos, pues, que, de los 2.323 vecinos mudéjares antiguos residentes en los lugares realmente afectados por la expulsión, fueron registrados, antes de embarcar en Cartagena, unos 366 (el 15,7 por ciento); pero si comparamos con

60. Por otras razones, la población seguirá disminuyendo: en 1654 el Concejo dice que son menos de 30 vecinos, y se reducen a 14 en 1664. Al inicio del siglo XVII recomienza el ascenso con 22 familias.

61. José María GARCía Avilés (2007), Los moriscos del valle de Ricote, Alicante, Universidad, calcula que la expulsión del Valle de Ricote afecto a unos 432 vecinos, el $55 \%$ de la población, tomando como referencia los datos aportados por JUAN IGNACIO GUTIÉRREZ NIETO (1969), «Evolución demográfica de la cuenca del Segura», en Hispania, n 111, pp. 25-115 [48], asignados en torno al año 1620, cuando, en realidad, se refieren a 1648 .

62. Cf. Luis Lisón Hernández, RicArdo Montes Bernárdez y José Antonio Marín Mateos (2007), El Señorío de Cotillas y los Marqueses de Corvera (ss. XVII-XVIII), Murcia, pp. 181-182. Algo parecido ocurrió en Archena, donde fray Antonio Soriano, religioso del hábito de San Juan, que atendía la parroquia, pidió ayuda económica al Príncipe Filiberto, en Cartagena, el día 22-XII1613, porque sin vecinos no tenía con qué sustentarse, por lo que pedía las casas y haciendas de los deportados hasta que poblara de nuevo el lugar; AGS, Estado, leg. 252. Carta del Príncipe Filiberto al Rey, Cartagena, 22-XII-1613. 
el primer censo inmediato del que disponemos, los expulsados serían, al menos de 789 casas (el 33,96 por ciento): unas 3.550 personas, número que quizá sería mayor, ya que, en este cómputo, no contamos con los datos de las aldeas de Mula y, además, en el año 1631, algunos de los expelidos habían vuelto.

En los registros de los embarques, repito, no figuran los pobres. Pero no sólo salieron por Cartagena los expulsados: otros eligieron un camino clandestino, hacia el Reino de Valencia, a localidades más seguras dentro del Reino de Murcia... con la esperanza de regresar algún día. Algunas doncellas y viudas casaron, evitaron el exilio de España, pero sufrieron igualmente el desplazamiento de su tierra, como tantos otros que cambiaron parte de su identidad para evitar el exilio. Su lugar permanecería sin ocupar durante casi un siglo, pues al destierro se unió el hambre y las epidemias que azotan hasta finales del siglo XVII.

\title{
RESUMEN
}

Cumplidos los 400 años de la expulsión de los moriscos españoles (16091614), los historiadores siguen debatiendo por qué se decretaron los edictos de expulsión, cuál fue el número de moriscos que finalmente abandonaron los reinos de Felipe III y cuál era su origen geográfico. Junto a los granadinos dispersos por Castilla, fueron deportados los descendientes de los mudéjares, obligados en 1502 a bautizarse o a abandonar España. La situación de las aljamas mudéjares castellanas en este periodo la describió Miguel Ángel Ladero Quesada a partir de los recuentos fiscales de fines del siglo XV y principios del XVI. El 20 por ciento de esta población se localizaba en el Reino de Murcia, y fue el último grupo afectado por tan grave decisión.

Palabras clave: moriscos, mudéjares, Murcia, expulsión 1614.

\begin{abstract}
Reaching the $400^{\text {th }}$ anniversary of the Spanish Moriscos Deportation (1609-1614), historians continue to debate why the edicts of Deportation were decreed, which was the number of moors who finally left the kingdoms of Philip III and what their geographical origin was. Along with the granadinos scattered across Castilla, the Moriscos descendants were deported and porced in 1502 to be baptized or to leave Spain. The situation of the castilian mudéjar aljamas was described in that time by Miguel Ángel Ladero Quesada based on fiscal controls from late fifteenth and early sixteenth century. Twenty percent of this population was located in the Kingdom of Murcia, and it was the last group affected by such a serious decision.
\end{abstract}

Key words: moriscos, mudéjares, Murcia, deportation 1614. 